\title{
Patterns of Land Use Activities in Ghana's Secondary Cities
}

\author{
Bismark Mensah \\ Isaac Obeng Darkwa \\ Esther Bonful \\ Moses Bangfunourteru Tuu \\ Sanda Mohammed \\ Esther Yeboah Danso-Wiredu*
}

\begin{abstract}
Ghana is rapidly urbanizing. This urbanization has resulted in villages growing into towns and towns into urbanized areas. Theories and models have been employed to explain the internal structure of urban areas, especially, with respect to land use variations. These models started with the classical urban land use models in America. Urban scholars in Africa have struggled to fit the development of the African cities into these classical models. They have therefore called for African scholars to develop models for urban land use in Africa. This paper sought to identify the common patterns of land use activities which shape the internal structure of Ghana's secondary cities. The study employed Geographic Information System (GIS) as a major tool of analysis in explaining the patterns in urban areas. This is augmented with in-depth ground observations of the study areas. The findings of the study showed the absence of homogeneity in most of the sectors and undefined industrial zones as contradictions to the classical models. The study further revealed that residential zones were not fully occupied by either lower income, middle income, or higher income residence. The income groups may only dominate in a given sector. Based on the findings, a common pattern is proposed to represent the land uses within the selected secondary cities in Ghana.
\end{abstract}

Keywords: urban land use, common-patterns, internal structure, secondary cities, Ghana

Department of Geography Education, University of Education, Winneba *Corresponding author email: eydwiredu@uew.edu.gh

Ghana Journal of Geography Vol. 12 (2), 2020 pages 84-107

https://dx.doi.org/10.4314/gjg.v12i2.4 


\section{Introduction}

The paper examines the applicability of the western urban land use models to land use patterns in secondary Ghanaian cities. Theories and models have been employed to explain the internal structure of cities, especially in the context of land use variations. Popular among them is the classical American urban land use models: Concentric Zone Model by Burgess in 1925, Sector Model by Hoyt in 1939 and Multiple Nuclei Model by Harris and Edward in 1945 (Hoyt, 1964; Crowley, 1995). There has since been a number of similar models postulated globally to describe patterns of urban spatial development in different cities. Carlier and Ekeland (2004) discussed the economic determinants of the internal city structure and that positive externalities, create centripetal forces in Paris. Borsdorf, Hidalgo and Sánchez (2007) also developed a model of urban development in Latin America based on the increasing rate of gated communities in South America.

Mabogunje (1968) writing on urbanization of Africa claims that the classical models of urban structure that were developed in North America prior to 1945 cannot wholly be applied in African cities. This is largely because the urbanization processes in developing countries appear to differ from those of developed nations (Bao et al., 2007), where these classical land use models were developed. For instance, the UN-Habitat (2016) reports that the ongoing processes of urbanisation in developing countries. This consequently, produces land use competition that creates problems with the harmony and equity of urban land use. Angel et al. (2011) adds that the lack of effective urban governance in developing countries coupled with poor spatial planning systems to control urban growth for sustainable development is the major problem. The consequence of these problems is the seemingly haphazard spatial development within the urban space of developing countries like Ghana (Fuseini, 2016; Cobbinah et al., 2016).

There are multiple and conflicting factors which determine developers' decisions on how best to plan the city (Waddell \& Ulfarsson, 2004). This is responsible for the kind of land use distribution that occurs within a city. Generally, these factors are grouped into demographic, sociological, legal, political and economic (McDonagh \& John, 1995). Three of these factors tend to drive demand according to McDonagh and John (1995) and include demographic, economic and sociological factors. McDonagh and John (1995) further explain that economic factors are integrated in the decision-making tools, helping to choose between various alternatives (Andreas et al., 2010). The legal and political factors create the framework, which determines how development patterns take place for the general benefit of society (Andreas et al., 2010). In Ghana, however, as stated by Danso- 
Wiredu and Midheme (2017), social ties is a major factor that accounts for how housing patterns for example are arranged, and this has a considerable toll on the land use patterns that emerge in urban areas. Settlement planning in Ghana began in 1963 with the publication of the National Physical Development Plan (1963-1970) (Ministry of Land and Natural Resources, 2015). NPDP proposed that a set of urban settlements should be planned to achieve equitable and economic distribution of social and economic infrastructure and provide commercial and social functions to all Ghanaians.

Although there is much literature on the spatial structure of Western cities, especially the American cities such as Los Angeles (Gordon \& Harry 1996), Atlanta (Gong \& James 2002) and Randstad in Holland and Southern Californian urban region (Clark \& Marianne1994), only a few scholars have studied the urban spatial functions of African cities, including cities in Ghana (Fuseini, 2016; Amanfu, 2017; Kpienbaareh \& Luginaah, 2019; Appiah et al, 2014; Agyeman, 2020). In Ghana, the few studies conducted have focused on the big cities, that is, Accra-Tema, Sekondi-Takoradi and Kumasi (Fuseini 2016; Agyemang, 2020). Fuseini (2016) for instance, studied the urban governance and spatial planning systems for sustainable development in Tamale. Fuseini's focus was on how ineffective urban governance and poor planning system in Tamale are driving haphazard land-use. He did not attempt to model those haphazard land-uses occurring in the city of Tamale. Appiah et al (2014) explored peri-urban land use changes in Kumasi. Agyemang (2020) on the other hand, examined the growth of informal cities in Accra and Kumasi. His studies find urban growth in both cities to be highly spontaneous and rapid and that new developments fast turn into urban growth nuclei.

This paper examines the applicability of the American urban land use models to land use patterns in some selected secondary cities of Ghana: Sunyani, Koforidua, Cape Coast, and Takoradi. In Ghana, Accra and Kumasi are the primary cities in the country. They are the only cities with population of over a million. They are, therefore, non-comparable to any other city in the country in terms of their economic, social and political functions as well as population sizes. In this study therefore, secondary cities are defined as all capital towns in Ghana with the exception of Accra and Kumasi. Those cities have a reasonably diversified economic base and a substantial labour force who work in other sectors of the economy apart from the primary economic activity sector.

The paper seeks to answer the question on whether there are common patterns of development that run through the land use activities in Ghana's secondary cities? The paper is presented in three main parts. The first part of the paper deals with the descriptions of the classical North American urban land use models. The second part describes the spatial characteristics of the internal land use patters 
within the selected secondary cities in Ghana and the third part of the study covers a discussion on the selected secondary cities, providing a relatively representative scope to understanding the general urban land use patterns within secondary Ghanaian cities.

\section{Classical Theories of Urban Land Use}

The need to study the urban morphology started from the chicago school (Brown, 2011) was the first to develop the concept of social ecology where he applied plant and animal ecology to the city development. To him, the city is a product of nature, and in particular of human nature. Therefore, the city, which is seen as a community, can also be seen as organism (thus, population linked to a territory) and there is symbiotic dependence of individual's natural mechanism that regulates size of organism and balance between individuals (Hess Jr, 1995; Owens, 2012). The processes also create a succession of growth at different stages, which led to the propounding of different urban land use models, beginning from American cities, which are briefly discussed below:

Concentric model: Burgess devised the concentric growth model based on the pattern of growth of Chicago city (McDonagh, 2007). The model explains that a city expands from its original centre toward the periphery in a series of concentric zones. Burgess identified five zones/rings. The central business district (CBD) or loop is a commercial Centre that contains offices, stores, retailers, financial institutions and hotels (Figure 1). The second Zone is in transition made up of older deteriorating homes, factories, and other businesses. Their proximity to zone three eases their access to labour and market. Zone three is the dwelling of wage workers and first-generation immigrants of the CBD. The fourth zone comprises of better residence of middle-income workers while zone five is made up of commuter zone consists of single-family dwellings of high-class apartment buildings (McDonagh, 2007). 


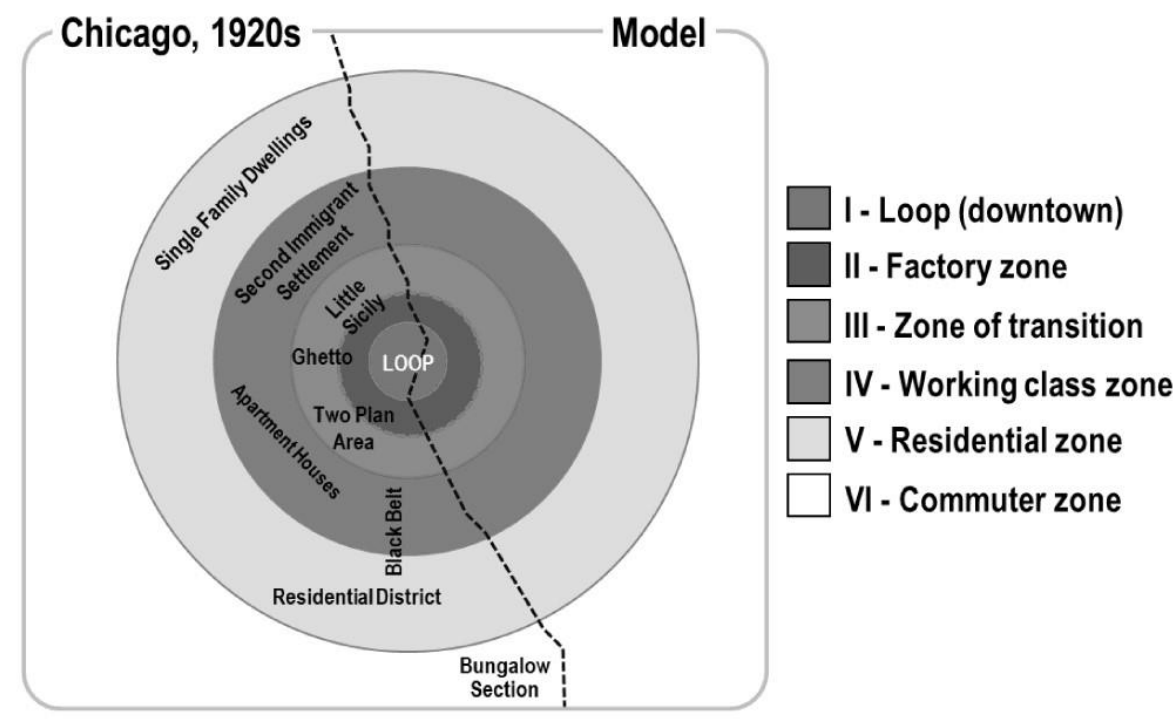

Figure1: The Concentric Model

Adapted from Brown, 2011

Sector model: Hoyt (1939) developed the sector model to generalize on urban internal structure upon studying urban processes during the pre-World War II. According to Hoyt, instead of cities developing in concentric forms as observed by Burgess (1925), they rather develop in wedges or pieshape zones and corridors developed from the core of the city to the outskirts along major transportation routes. In the Hoyt Sector Model, the Central Business District (CBD) remains in the center, but expanding outward away from it along transportation lines, are zones used for industrial and residential developments. The model asserts that land use within each sector is homogenous. Rent levels differentiate the sectors (McDonagh, 2007). Hoyt's theory also emphasized topographical factors in that, high-priced housing would move towards high ground, undeveloped water fronts, land with views, or similar areas with natural beauty, and away from, but, handily accessible to high speed transportation routes. He also observed that there is a gradient of rentals downwards from these high rental areas in all directions. For this reason, low-income housing tended to be as far away as possible from high-income areas and nearest to industrial sites or other low amenity factors (McDonagh, 2007) as shown in figure 2 . 
Central business

district (CBD)

Wholesale, light

manufacturing (transitional)

Low class

residential

Medium class

residential

High class

residential

Figure 2: The Sector Land Use Model

Source: Adapted from Tim Hall, 2006

Multiple nuclei model: The theory was developed by Harris and Ullman in 1945 and revised in 1962 (Berry, 2004). The basic assumption of this theory is that cities are not homocentric but they rather have many mini centers, which play a significant role in the development of a city. These mini centers originally developed independently with the specialized advantages that they offered or similar activities clustering in these areas. Multiple nuclei theory differs from the earlier theories. It believes that city has not developed around a single Centre or CBD but it has a group of many mini centers. However, the phases of development may be simultaneous or in different periods. The multiple nuclei type is further divided into major areas (McDonagh, 2007; Asamoah, 2010) as shown in figure 3. 


\section{Harris and Ullman's Multiple Nuclei Model}
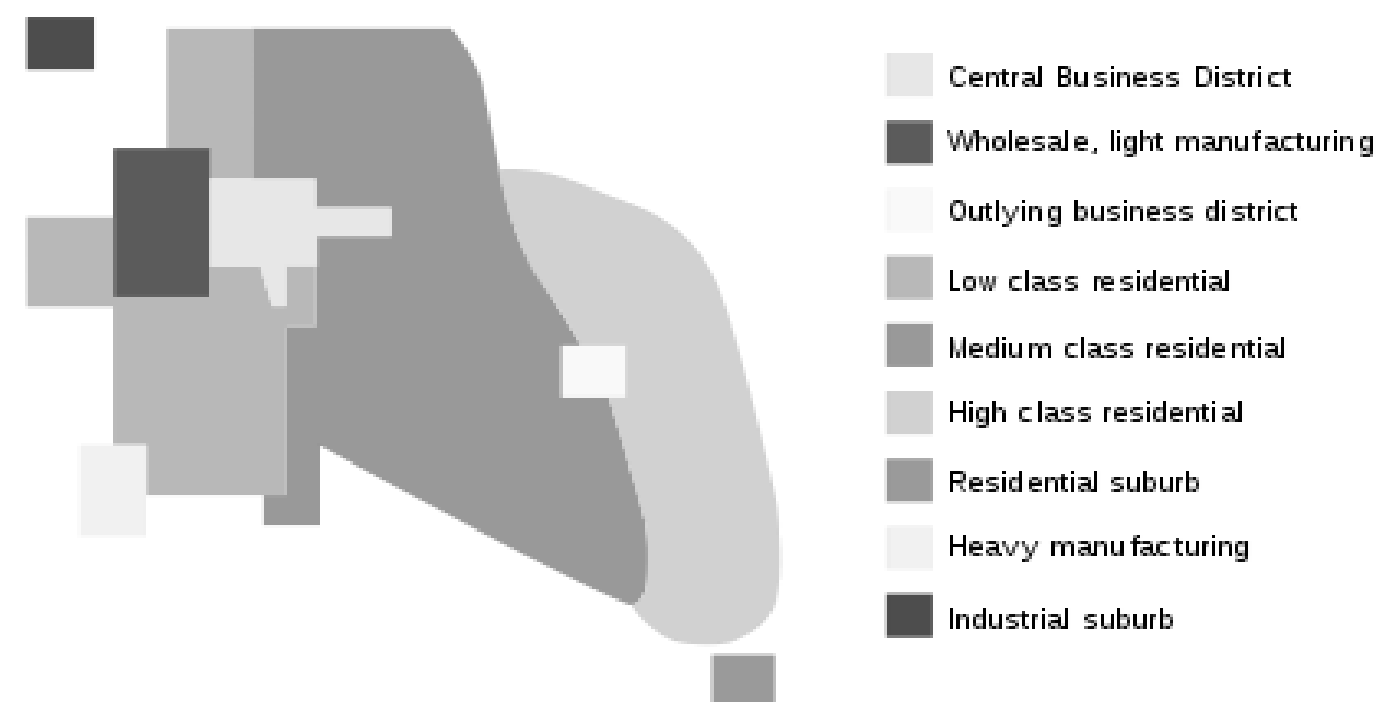

Figure 3: The Multiple Nuclei Model

Adapted from Tim Hall, 2006

\section{Methods and Approaches of Explaining Internal Urban Structure}

There have been many methods and approaches that have since the development of the American urban land use models, been used in developing knowledge on the nature of urban land uses and the structures of urban growth. Theories about the internal structure of cities are many. Example include various theoretical paradigms including the human ecology school, neoclassical urban economics, conflict and urban managerialism and the neomarxist approach (Yeh \& Wu, 1996). The different approaches provide different explanations on the internal structure of cities. These methods or approaches explore urban development in a general sense including land development process. For example, Reginster and Rounsevell (2006) explored the scenarios of future urban land use in Europe; Petrov, Lavalle and Kasanko (2009) also studied the urban land use scenarios for a tourist region in Europe by applying the MOLAND model to Algarve, Portugal. Guan et al (2011) on the other hand, modelled urban land use change in Saga, Japan and Braimoh and Onishi (2007) studied spatial determinants of urban land use change in Lagos, Nigeria. Are the American classical urban models still relevant in any of the recent models? The answer is yes, because they are based on key features of urban development, which have persisted over the years and either some, or all the land use features discussed in the models form the basis for all urban land use studies. These land use features include the CBDs (which form the commercial and business centre of every city), forms of manufacturing, residential differentials and physical infrastructures. This study contributes to this debate by 
identifying the common land use patterns that define the growth of Ghana's secondary cities based on their own socio-economic functions and focusing on the main land use features used in modelling the American land use activities from a purely qualitative point of view using GIS.

\section{Research Settings and Methods}

This study involves a combination of a desktop systematic literature review to study the classical urban land use models and other models and methods of studying urban land use activities developed afterwards. It also employed Geographic Information System (GIS) as the tool for mapping patterns of land use activities within the selected secondary cities whiles making use of in-depth ground observations and experiences of the researchers of the studied cities. At least one of the researchers has lived in one of the selected cities for not less than ten years. Interviews of stakeholders of the study cities were also conducted to add to the validity of the findings.

The study focused on selected secondary cities in Ghana as earlier explained by definition. All the cities selected are the capital towns of their respective regions in the country. The towns selected do not include the two main primary cities in the country (Accra and Kumasi) this is because a number of researches have already been done in those two cities. The selected towns were purposively selected based on convenience of the researchers. The selected towns do not therefore; represent the totality of urban land use activities in Ghana. That notwithstanding, their experiences are similar to what prevails in other parts of the country. The cities selected are briefly discussed below:

Sunyani municipality per the 2010 Population and Housing Census (PHC) was established on $10^{\text {th }}$ March 1989 (Ghana Statistical Service, 2014). Sunyani is the capital of the then Brong- Ahafo Region and now the Bono Region. It covers a total land area of $506.7 \mathrm{~km} 2$, housing a total population of 123,224 (Ghana Statistical Service, 2014). Sunyani hosts numerous health and educational facilities, both public and private. The city has an airport, a big market with good road network within the city and linking neighbouring towns, making it a centre of trade (Ghana Statistical Service, 2014).

Sekondi-Takoradi covers a land area of $219 \mathrm{~km} 2$ with Sekondi as the administrative headquarters. The Metropolis is bordered to the west by Ahanta-West District, to the north by Mpohor Wassa East District, to the east by Shama District and south by the Gulf of Guinea. The population of SekondiTakoradi, based on Ghana's 2010 Population and Housing Census was 559, 548 (Ghana Statistical Service, 2014). The city is also informally called the 'Oil City of Ghana', due to the discovery of oil 
in the Western Region which has attracted migrants from all over the country and even around the world.

Koforidua serves as the administrative headquarters of the Eastern Region and the capital of New Juaben Municipal Assembly. It is located about 85 kilometers north-west of Accra and west of the foothills of the Obuotabiri Mountains. Koforidua covers an area of $110 \mathrm{~km}^{2}$, constituting $0.57 \%$ of the total land area of the Eastern Region (Dickson et al, 1988). The total population of the New Juaben Municipality according to the 2010 Population and Housing Census is 183,727 (Ghana Statistical Service, 2014).

Cape Coast is the former administrative capital of Ghana. It serves as the administrative capital of both the Metropolitan area and the Central Region of Ghana. It was the only noticeable urban center in the metropolitan area in 1984 (Ghana Statistical Service, 2014). According to the Ghana's 2010 Population and Housing Census, Cape Coast Metropolis has a population of 169,894 (Ghana Statistical Service, 2014).

To do further pattern analysis, the selected cities were viewed aerially using Google Earth. A Map showing the study areas is presented in Figure 4. 


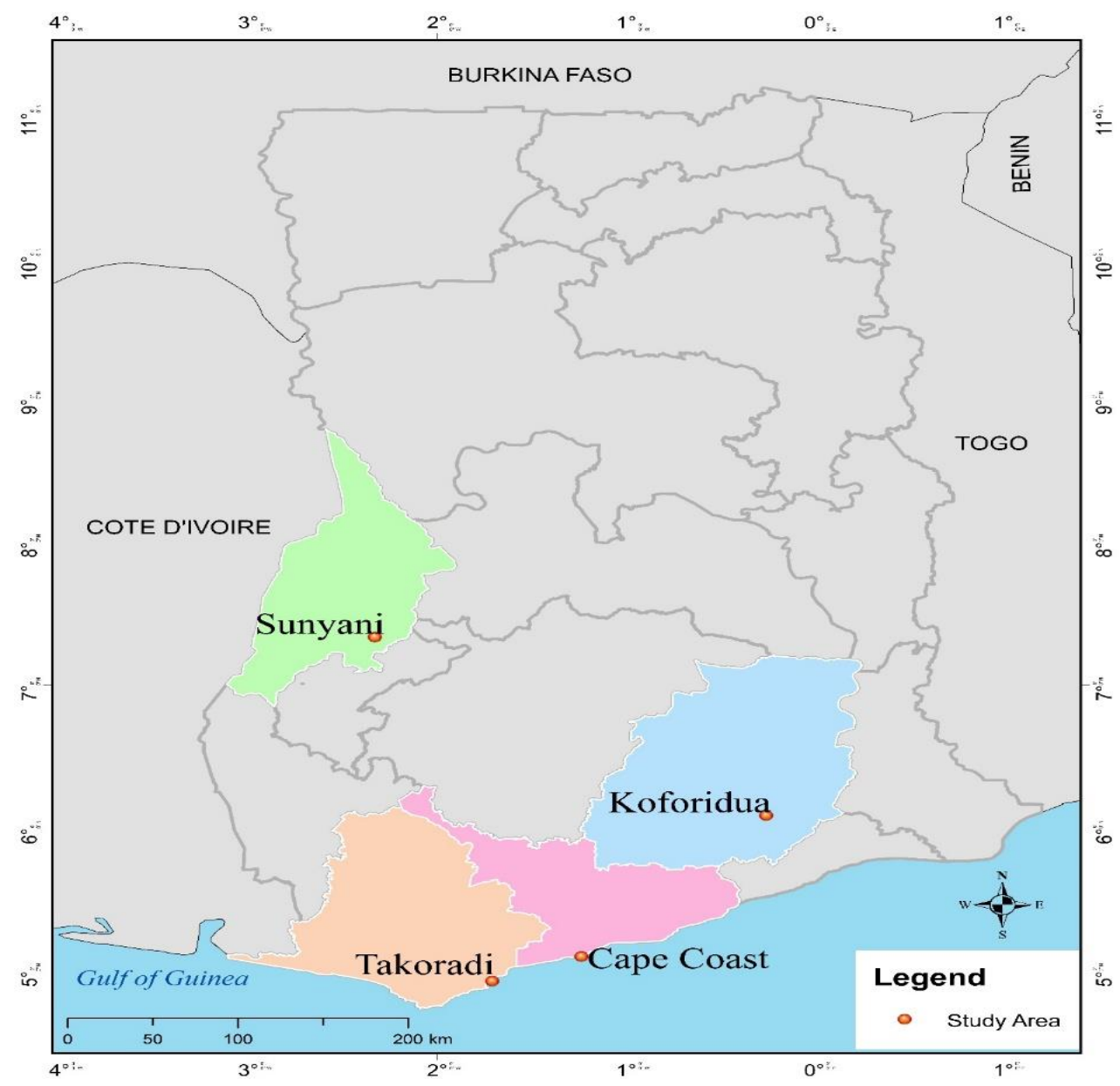

Figure 4: Map of study areas (Produced by authors using GIS, 2019).

\section{Description of The Internal Land Uses in The Study Areas}

In this section, the researchers provide a vivid description of the selected secondary cities in Ghana based on the internal spatial structure of the land use activities. As earlier stated, the main land use features, which form the parameters for the classical urban land use models are basically, the location of the CBDs, residential places and manufacturing sectors. These parameters were the basis for the data collection within the selected cities in addition to visibly found social and physical infrastructures.

\section{Sunyani}

The CBD of Sunyani is centered at the main taxi rank, which houses most of the banks, shops, and other offices. North of the CBD from Zongo one-way road, most of the houses are old compound houses and could represent the transition zone postulated by the Burges (1925) in the concentric zone 
land use model. The Airport Residential area and its surroundings form a commuter zone. The houses gradually change to single apartments as well as flats, especially, around the Airport Residential Area. To the north-east, the ring breaks because of the regional hospital and Nursing Training College. South of the CBD is New Town extending along the Atronie road. This represents a transition zone. Further south is Estate Residential area extending up to the inner ring road, a new developing area with high cost single dwelling apartments forms the commuter zone. South-east along SunyaniKumasi road has little residential land use due to the presence of Sunyani Senior High School and Technical University, Jubilee Park and other offices. South-west is the regional administration site. In the west, consist of a number of residential areas up to the University of Energy and Natural Resources, which also form a commuter zone. These descriptions are mapped in figure 5.

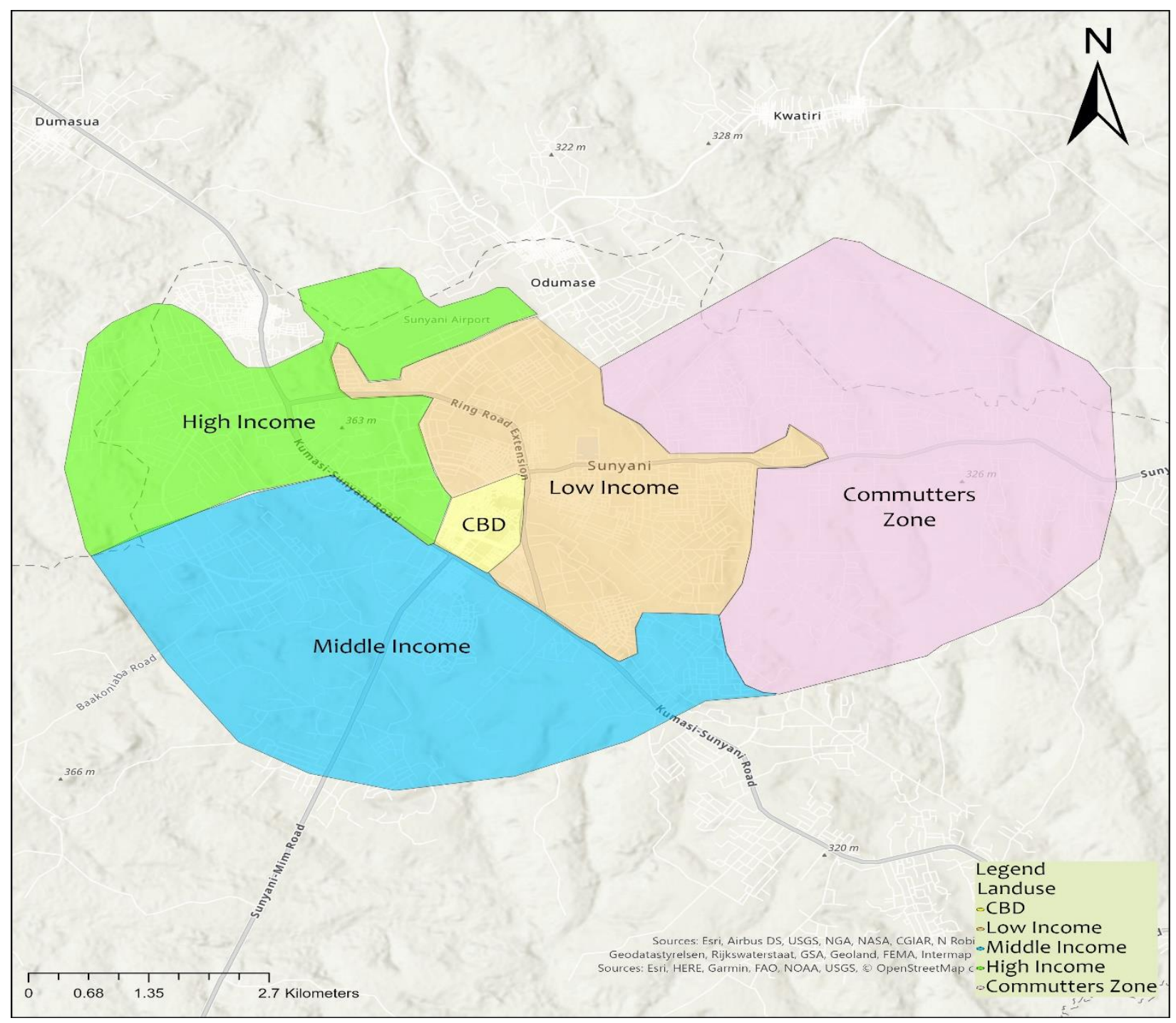

Figure 5: Mapping Land use Activities in Sunyani

To the east according to figure 5, in the inner ring, are found old buildings around the CBD. This gives way to single apartment buildings at the eastern side of the CBD. Similar houses extend further 
east to the outer ring road. There are also a number of uncompleted buildings at the outskirts of the town. Those buildings are mostly occupied by migrant-youth on hwesomame (meaning, look after it for me) agreement. This phenomenon is common in most cities in Ghana where migrant-youth live in peoples' uncompleted buildings whilst the owners build the houses incrementally (see also, Gough \& Yankson, 2011).

\section{Cape Coast}

From a critical observation of land use patterns in Cape Coast, Kotokoraba is the Central Business District. The area is filled with diverse commercial or economic activities ranging from banking, insurance and wholesale to retailing services. It is the center of Cape Coast. Here, headquarters of banking and insurance institutions are located. Inside the CBD is the New Market building, housing different businesses. The various residential sectors in Cape Coast are not very concentric. These sectors have developed along the road network in a wedge-shaped form. The low-income residential zone, which is closer to the CBD, for instance, is located to the southeast and south-west of the CBD. The middle-income zone and high-income residential zone are mostly in the northeast and north-west of the CBD respectively as shown on figure 6. 


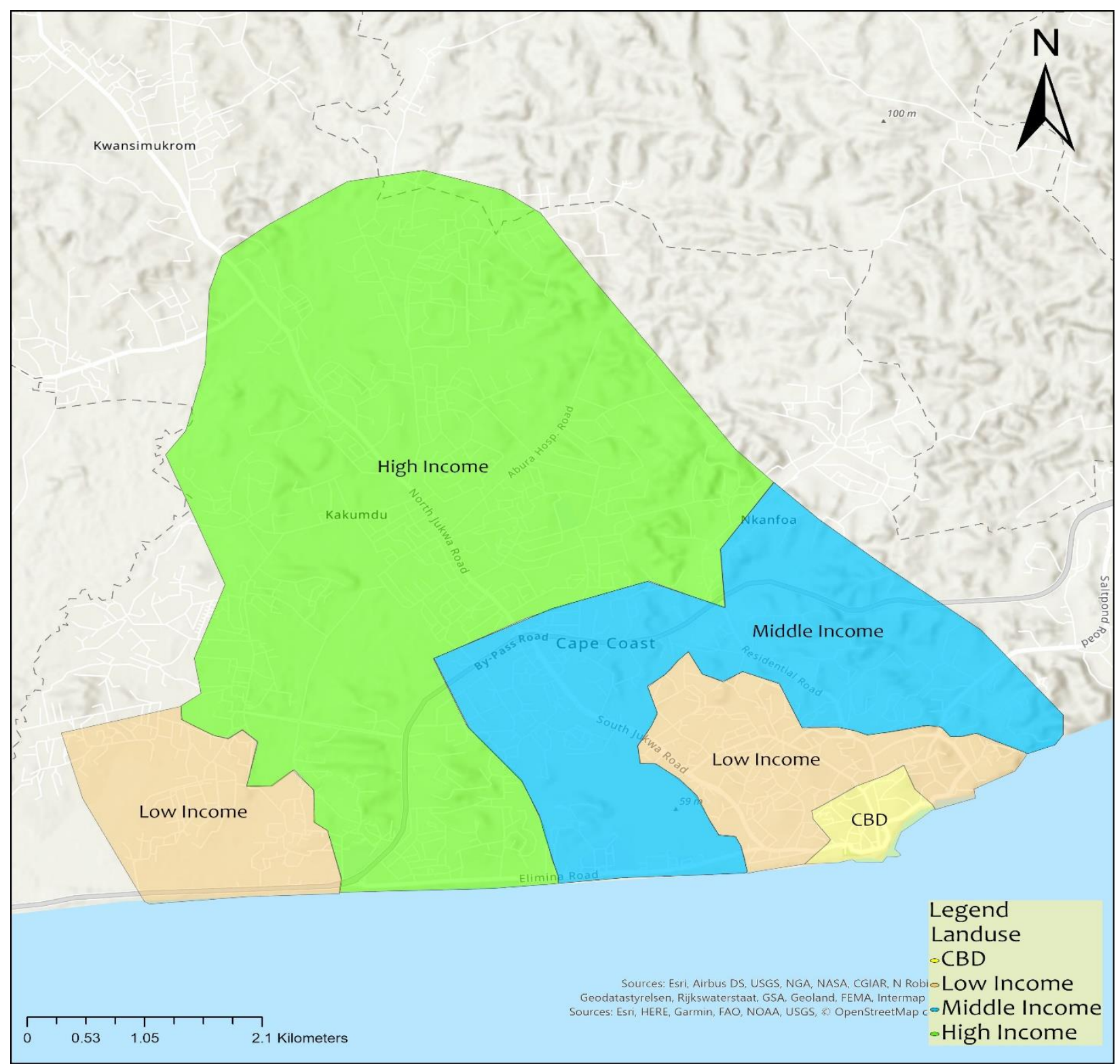

Figure 6: Mapping Land use Activities in Cape Coast

Inside the CBD of Cape Coast as seen in figure 6 are residential apartments. There is no clear-cut industrial zone in Cape Coast. The Ameen Sangari manufacturing company is isolated from the CBD. In addition to this, there seemed to be no total homogeneity within the residential zones. Thus, inside the middle-income residential zone are some patches of shattered and poor houses occupied by the low-income residents. Another sharp contrast is the scattered nature of the high-income houses. These contradictions perhaps give credence to Amanfu (2017) findings that, changes occurring in land use in Cape Coast stem from the lack of a comprehensive monitoring and supervision by the Building Inspectorate of Cape Coast Municipal Assembly as well as the various challenges faced by the Land Sector Agencies (Amanfu, 2017). There is an intersection between successive residential zones. This implies that, whiles low-income houses are found within middle-income residential zone, middle income houses are also found within high-income residential zone. Sometimes, it is extremely 
difficult to identify the transition from the middle to the high-income zones. In addition to this, is a sub-business district located in the high residential zone. Found in the newly developing areas are the hwesomame housing.

\section{Takoradi}

At the center of Sekondi-Takoradi is the CBD, popularly known as 'Market Circle.' It is a hub of activities such as marketing, shops/stores, banks and lorry stations. This is the business center where all forms of businesses are conducted. Most of the buildings here are two or three stories. Some of the buildings also serve as residential facilities, which is in sharp contrast to what is known in urban studies in the literature, but also becoming common in many urban areas in Ghana. The frontages of the buildings are rented out as stores while the back is used as places of residence. The shape of such buildings is circular in nature, commonly referred to as compound houses with many households. In Takoradi, few industries are found here. Most of the industries are located along the main road to Cape Coast, Sekondi and the harbour area. In Takoradi, the lower income zone is next to the CBD. Buildings here are made up of story apartments as well as individual residence. Most of such buildings are old and belong to early settlers. Few of them have been renovated to suit the growth of the city, giving rise to gentrification. The ground floor of some of them have been rented out as stores. Buildings here are clustered and small. Several households may occupy one house. Residents here are usually low-income earners. 


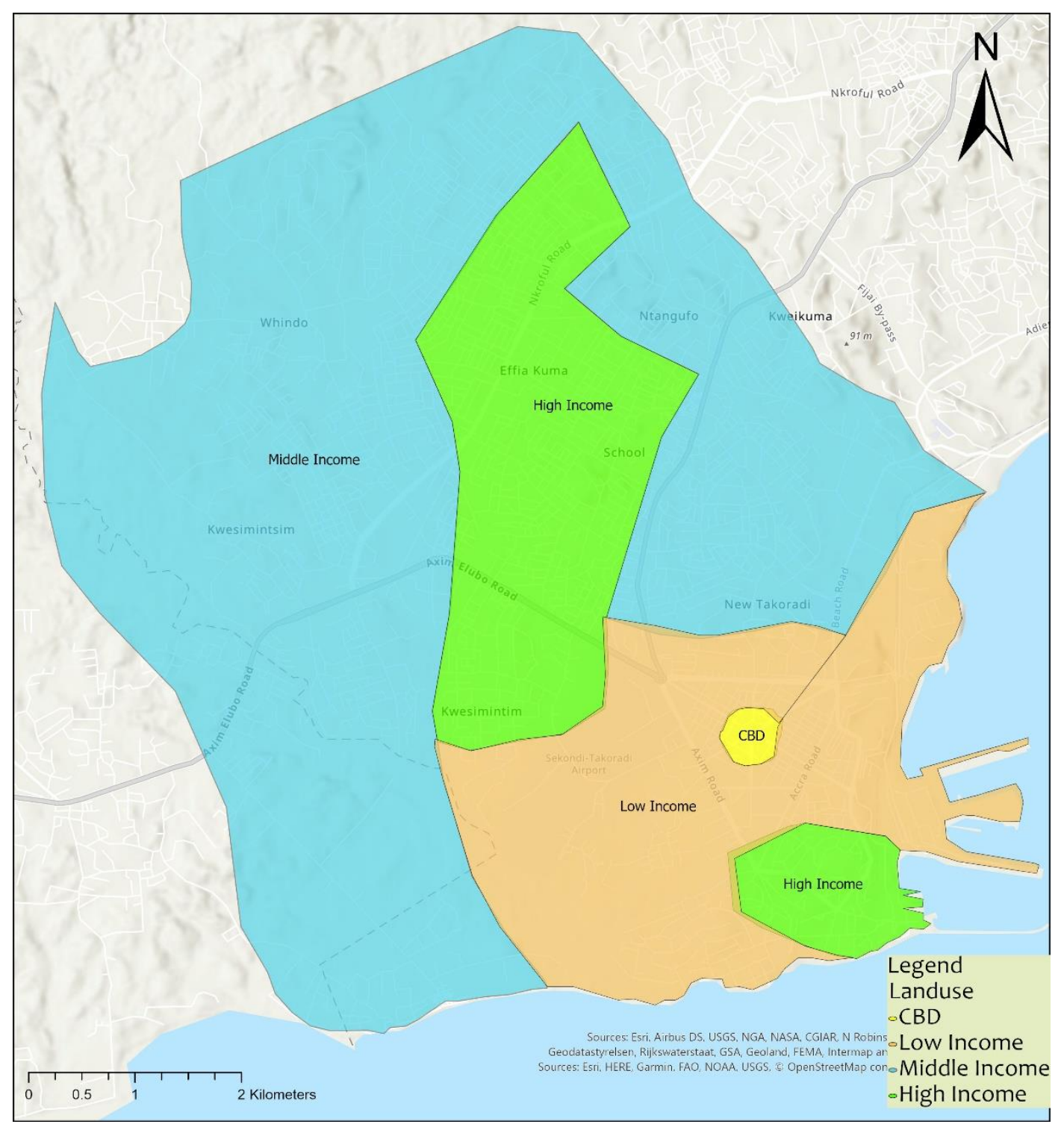

Figure 7: Mapping Land use Activities in Takoradi

Far away from the CBD as shown in figure 7 are also some low-class farming communities. The researchers observed that, the people living in these areas want to live close to their farms and most of them own the land and their houses, usually of sub-standard in nature. In addition, belonging to this zone are old fishing communities like the ones along the coastline as well as small-populated areas that are close to some heavy industries located on the main Cape Coast-Accra highway. There are two zones in the middle-class zone of Takoradi. One section is towards the Ghana Secondary Technical School (GSTS). The harbour, the railroad company, some churches as well as light industries are located in this area. The area is commonly known as quarters because houses here were built mainly for workers. The buildings range from one-to-two-bed rooms apartments whilst others are semi-detached. Now its occupants are mainly public sector workers such as teachers and nurses. 
They usually have their kitchens and bathrooms on the compound. Today, most of the quarters' buildings have been sold to the occupants who are mostly retirees and some active workers. The other middle-class-zone in Takoradi consists of individuals who have built their own houses. This area is towards the opposite side of the quarters.

The high-class residential zone is located at Chapel Hill, Beach Road and Anaji which few years ago had only estate houses for workers. Today, the area has extended widely after the construction of the Anaji- Kwesimintsim road. Huge and modern buildings are located here. This area has bungalows, which used to be the residence of the 'whites' during the colonial era. Most of the first-class hotels in the city are located in this area. It has also many spots and restaurants and located close to the beach. Many foreign investors are in Takoradi, especially, those who work in the oil fields live in this community. Another high-class area is the Airport Ridge. Per the name, this area is close to the airport. Years ago, only few houses built for the military officers who worked with the air force were found there. Now this area is classified as a high - class luxurious area with houses and hotels located there.

There are edge cities where we can have urban complexes consisting of large nodes of office buildings with more workers than there are residents. Few new buildings around the harbour area and Chapel Hill are used as offices as well as banks. The Jubilee Park that was built during Ghana's 50 years anniversary has now become ceremonial ground for cultural activities. The CBD has lost some of its importance since it was created, as many retail and office buildings have moved into the suburbs. This description somehow fits into the nuclei-land use model where, there seem to be multiple centres beside the main CBD. The newly developing areas also have the hwesomame concept there.

\section{Koforidua}

The center (CBD) is located at Juabeng Serwaa Market (Ogua Market) on the main Accra road. The Regional Hospital is adjacent to the All Nations University, which is on the main road to the Lorry station. It is obvious that the northeast wedge, represented by Adweso SSNIT Flat has a desirable residential location in Koforidua. Much of this is tied up with the amenity values offered by nearby park, undulating land surface as well as river frontages available to many properties in the area. After the initial development of inner northeast, there is later development of high-income residential housing in adjacent suburbs. Transportation routes radiating from the CBD are central to the development of sectors, as these represent the lines of least resistance. In the case of Koforidua northwest, these routes are primarily represented by Central Hospital - All Nations University Road. The 
ribbon type street frontage developments are also characteristic of the sector theory and this can be easily be found along the Koforidua-Accra Road in respect of motel development, and along the Total Filling Station Road in respect of commercial development.

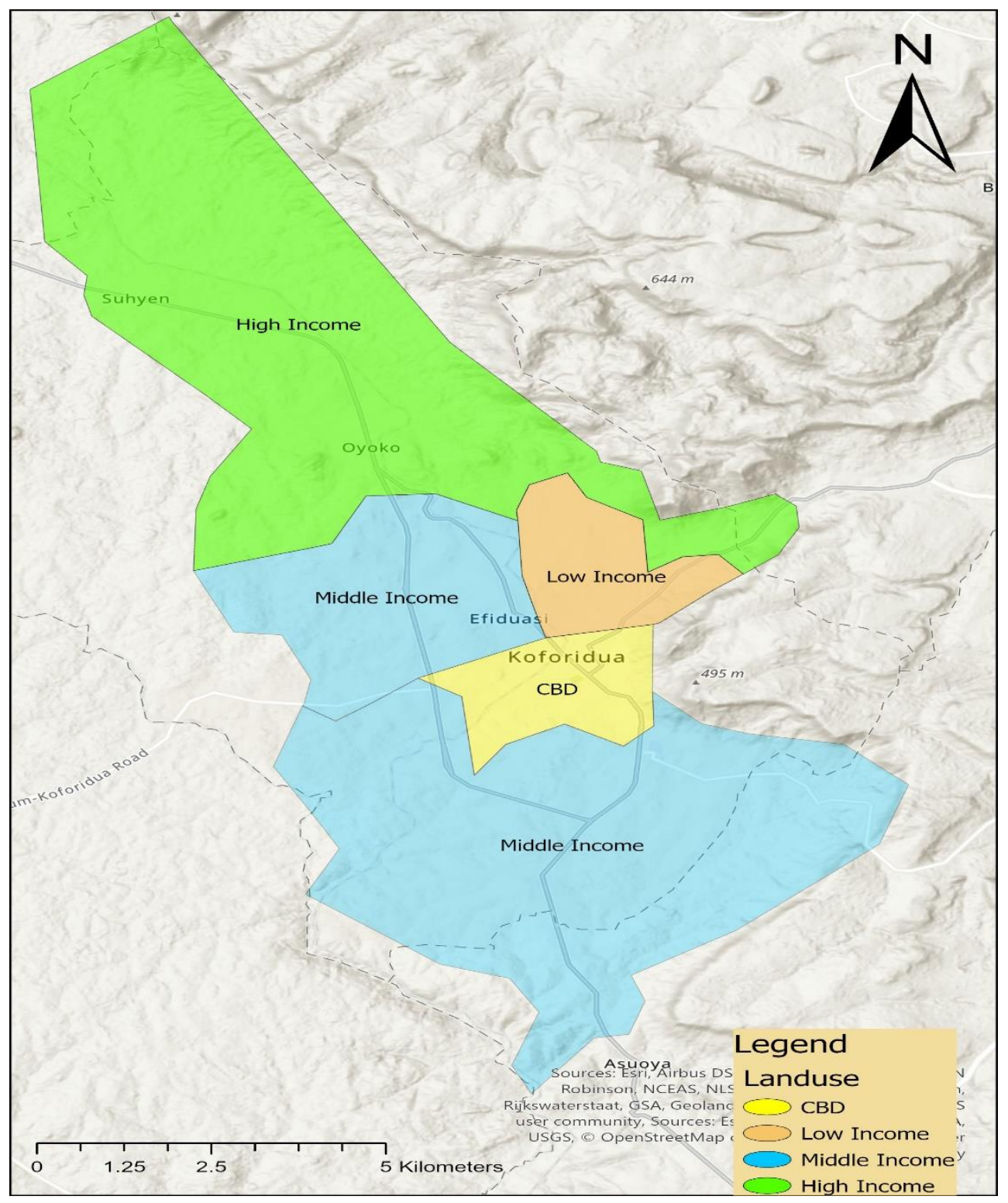

Figure 8: Mapping Land use Activities in Koforidua

The middle- and upper-income groups have built new housing on the outskirts of the city in new development areas off the Koforidua-Kumasi Road. The situation in Koforidua also reflects Hoyt's (1939) emphasis on topographical features influencing land uses. The high value land uses moved towards the river frontages and towards the hilly areas with their consequent views. Nevertheless, inexplicably, it can also be seen as high value areas as you move towards the Koforidua Stadium and little movement towards the largely underdeveloped waterfront areas of Jubilee Park. To the 
southeast, there is an extension of industrial activities along the main road in early times, which was the primary industrial transport route. In addition, in Koforidua, the newly developing areas also have the hwesomame housing.

\section{Common Patterns of Land Use Activities in the Study Areas}

Description of the main land use features in the selected cities comprises mainly; CBDs, residential facilities, manufacturing sectors and physical infrastructure, the study revealed similar patterns and a few contractions of land use activities in the selected cities. The findings of the study have shown that, whereas the Central Business District, the wedge-shaped residential zones and the presence of multiple nuclei can be seen as characterizing the Ghanaian secondary cities discussed the absence of homogeneity in most of the sectors and undefined industrial zones were typical contradictions. Based on this, the study identifies common land use patterns mapped for cities studied.

The underlying land use pattern for the studied secondary cities in Ghana include the fact that, there appears to be no homogeneity in the various sectors within the cities. For instance, the study revealed that in residential patterns, a residential sector might not necessarily be occupied solely by lowerincome residents, middle-income residents or higher-income residents. In other words, it is not likely from the description of the internal land uses within the secondary cities studied, that an area or a residential sector may be fully thronged with low-income housing, middle-income housing, or higherincome housing. Typically, the study revealed that areas dominated by middle-income housing are also found patches of lower-income housing. Further, within the higher-income zones are not only higher-income housing, but also the presence of patches of middle-income housing. This hinges on the social ties that is characteristic of the Ghanaian family system as revealed by Danso-Wiredu (2018). Thus, a higher income person who may be able to afford high value land within the highincome areas may decide to build his/her house within a middle-income zone due to family or communal land ownership. What the study portrays from the evidence in figure 9 is that, it is possible to have a mixture of middle and higher-income houses in the same area, and lower and middle-income houses also in the same area. It is, however, not common to have a lower-income and higher-income houses in the same area. This is because most high-income areas in the cities studied belong to worthy migrants who have bought their private land for development; indigenous houses are therefore absent in these areas.

Moreover, due to the development of transportation system, which links, even the outskirts of the studied cities to the CBD, some middle and low-income residents live further away from the center 
of the city. The reason for this is also linked to the fact that land and rental accommodation is expensive in the inner cities but affordable at the urban fringes. In addition to the poor living in the decaying houses in the inner cities of the study areas, it is common to have many poor people also living in people's uncompleted houses in the urban fringes. The hwesomame phenomenon is also discussed in the literature (see also Gough and Yankson 2011; Danso-Wiredu, 2016). For instance, as noted in the case of Takoradi, low-income residents build their houses close to their farms, further away from the CBD. In view of this, some low-income residents may not necessarily stay in areas close to the CBD.

The study again revealed, similarly to the Concentric and Sector land use models discussed, that most economic activities are concentrated in the CBD, but there was evidence of other CBDs in other suburbs of the studied cities similar to the multiple nuclei land use models. Industries are not conspicuously found in all the studied cities located in clearly defined zones, but, the study revealed that industrial locations are scattered in the studied cities, with the most common one being water packaging and food processing industries.

However, various city planners have laid down suppose land use activities on paper, evidence based on numerous researches conducted in the country shows that there are other factors, which influence land use activities in cities in Ghana. These factors which were also evident in the findings include land ownership, land usually belongs to the traditional leaders who sell land without prescribing to the buyers what the land should be used for (Ubink \& Quan, 2008; Amanor \& Ubink, 2008; ArkoAdjei, 2011). People, therefore, buy land in similar areas for varying purposes. Population growth is another factor, which determines how the urban land is used (Kleemann et al., 2017; Doan \& Oduro, 2012; Cobbinah \& Amoako, 2012). Usually, people are concentrated in deprived areas in the cities or become caretakers at the urban fringes for lack of enough money to rent houses. The emergence of makeshifts structures in urban areas is attributable to this phenomenon. Governmental policies and interventions such as building of roads, schools and monumental infrastructure like the Jubilee Parks naturally induce development in these areas (Owusu-Ansah \& O'Connor, 2006; Adarkwa, 2012). Commonly among them are new houses being built in such areas. For lack of goodwill on the part of municipal planners (Fuseini \& Kemp, 2016; Korah \& Cobbinah, 2017; Korah, Cobbinah \& Nunbogu, 2017) to insist on the right usage of the urban land in Ghana has resulted in haphazard land usage, which is difficult to model by researchers.

The findings discovered by the researchers are combined to propose a pattern of land use activities for internal spatial structures of Ghana's secondary cities below. 


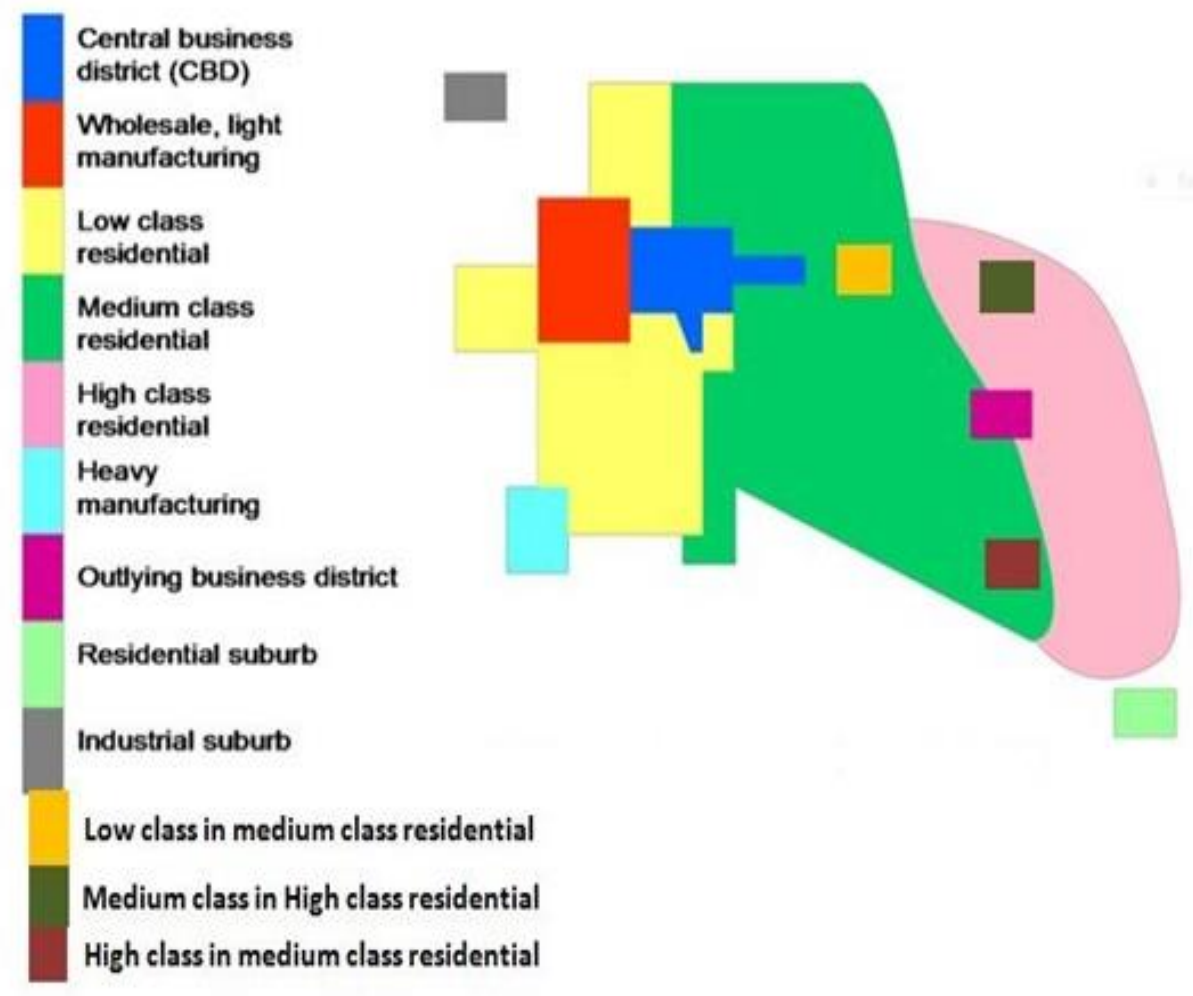

Figure 9: Common patterns of land use activities in Ghana's secondary cities

\section{Conclusion}

Until date, no acceptable common spatial planning policy is seen implemented in Ghanaian cities. It is therefore important that urban planning practitioners and researchers agree on standardized patterns of growth in Ghanaian cities. It is based on this premises that, the study sought to re-visit the classical urban land use models developed in the western countries, specifically that of the American cities to look into common characteristics that explain land use patterns in Ghana's secondary cities. The study found out that several cities globally have been modelled based on the internal structures as well as on social and economic factors. Like many cities mapped out based on the internal structures, some specific land use activities in a few Ghanaian cities have also been studied and mapped as discussed in the work. These include the Agricultural landscape of Tamale and Tachiman; the evolution of the spatial structure of Kumasi; the mapping of peri-urban areas in Kumasi and Tamale and the mapping of the socio-cultural dynamics of the city of Wa, Accra and Kumasi. The study adds to the above studies by looking at the qualitative descriptions of internal structures of land use activities of the studied cities thereby identifying common characteristics that explain land use patterns in the study 
areas. The researchers hope this will provoke further studies to induce a generalized land-use activities model for secondary cities in Ghana.

The research revealed that as much as the classical land use models provide a somewhat satisfactory explanation to patterns of urban land use in developed economies, in particular, America, they perhaps do not provide a comprehensive or a wholesome description of urban land use patterns in most cities of developing countries. From the detailed description of the structure of land use activities of the selected secondary cities, it is clear that the pattern of urbanization occurring in Ghana differ from urbanization processes occurring in developed countries because of mainly social, political and demographic differentials in Ghana. The peculiarity of the land uses in the Ghanaian cities may be because of the framework and institutions that control spatial planning within cities as well as the human response behaviours to the prevailing conditions.

The policy recommendation made by this study is that, there is no homogeneity in terms of land use development in the secondary cities studied. City planners and related stakeholders should therefore, study each city carefully and develop the necessary planning policy tools at the local levels. Researchers and city planners can further study the common identified urban land use pattern. As already stated, this pattern was arrived at because of researchers' experiences of their known cities, observations and the use of GIS to map the identified pattern. The authors therefore agree that factors such as governmental policies, socio-cultural practices and local economies also play vital role in the development of an established model.

\section{References}

Adarkwa, K. K. (2012). The changing face of Ghanaian towns. African Review of Economics and Finance, 4(1), 1-29.

Amanor, K., \& M Ubink, J. (2008). Contesting land and custom in Ghana. State, chief and the citizen . Leiden University Press.

Agyemang, F. (2020). Dynamic geospatial modelling and simulation of predominantly informal cities: an integrated agent-based and cellular automata model of urban growth (Doctoral dissertation, University of Cambridge).

Agyemang, F. S., Silva, E., \& Poku-Boansi, M. (2019). Understanding the urban spatial structure of Sub-Saharan African cities using the case of urban development patterns of a Ghanaian cityregion. Habitat International, 85, 21-33.

Amanfu, A. Y. (2017). "Examining the urban land management practices in Cape Coast. PhD Thesis, University of Cape Coast. 
Andreas, G., Allen, J., Farley, L., Kao, J. K., \& Mladenova, I. (2010). Towards the development of a rating system for sustainable infrastructure: A checklist or a decision-making tool? Proceedings of the Water Environment Federation, (2), 379-391.

Angel, S., Parent, J., Civco, D. L., Blei, A., \& Potere, D. (2011). The dimensions of global urban expansion: Estimates and projections for all countries, 2000-2050. Progress in Planning, 75(2), 53-107.

Appiah, D. O., Bugri, J. T., Forkuo, E. K., \& Boateng, P. K. (2014). Determinants of peri-urbanization and land use change patterns in peri-urban Ghana. Doctoral dissertation, Kwame Nkrumah University of Science and Technology. ir.knust.edu.gh

Arko-Adjei, A. (2011). Adapting land administration to the institutional framework of customary tenure: The case of peri-urban Ghana (No. 184). Amsterdam, the Netherlands: IOS Press.

Asamoah, B. (2010). Urbanisation and changing patterns of urban land use in Ghana: policy and planning implications for residential land use in Kumasi (Doctoral dissertation). Kwame Nkrumah University of Science and Technology. ir.knust.edu.gh

Bao, H., Li, Z., \& Wang, T. (2007). Conceptual model of sustainable development in sanddesertification region, China. Scientia Geographica Sinica, 27(2), 173.

Berry, B. J. (2004). Chauncy D. Harris, 1914-2003. Urban Geography, 25(1), 1-13.

Borsdorf, A., Hidalgo, R., \& Sánchez, R. (2007). A new model of urban development in Latin America: The gated communities and fenced cities in the metropolitan areas of Santiago de Chile and Valparaíso. Cities, 24(5), 365-378.

Braimoh, A. K., \& Onishi, T. (2007). Spatial determinants of urban land use change in Lagos, Nigeria. Land use policy, 24(2), 502-515.

Brown, N. (2011). Robert park and Ernest burgess: Urban ecology studies, 1925. Center for Spatially Integrated Social Science.

Carlier, G., \& Ekeland, I. (2004). The structure of cities. Journal of Global Optimization, 29(4), 371376.

Clark, W. A., \& Kuijpers-Linde, M. (1994). Commuting in restructuring urban regions. Urban Studies, 31(3), 465-483.

Cobbinah, P. B., Poku-Boansi, M., \& Asomani-Boateng, R. (2016, December). Urbanisation of hope or despair? Urban planning dilemma in Ghana. In Urban Forum (Vol. 27, No. 4, pp. 415-432). Springer Netherlands.

Cobbinah, P. B., \& Amoako, C. (2012). Urban sprawl and the loss of peri-urban land in Kumasi, Ghana. International Journal of Social and Human Sciences, 6(388), e397.

Crowley, W. K. (1995). Order and Disorder: A Model of Latin American Urban Land Use. Yearbook of the Association of Pacific Coast Geographers, 57(1), 9-31.

Danso-Wiredu, E. Y. (2016). The puzzles of living in urban poor communities: The role of informal governance structures in housing provision in Accra and Winneba, Ghana. Doctoral Dissertation, KULEUVEN. lirias.kuleuven.be

Danso-Wiredu, E. Y. (2018). Housing strategies in low income urban communities in Accra, Ghana. GeoJournal, 83(4), 663-677.

Danso-Wiredu, E. Y., \& Midheme, E. (2017). Slum upgrading in developing countries: lessons from Ghana and Kenya. Ghana Journal of Geography, 9(1), 88-108.

Dickson, K. B., Benneh, G., \& Essah, R. R. (1988). A new geography of Ghana (Vol. 34). London: Longman.

Doan, P., \& Oduro, C. Y. (2012). Patterns of population growth in peri-urban Accra, Ghana. International Journal of Urban and Regional Research, 36(6), 1306-1325.

Fuseini, I. (2016). Urban governance and spatial planning for sustainable urban development in Tamale, Ghana. Doctoral dissertation, Stellenbosch: Stellenbosch University. 
Fuseini, I., \& Kemp, J. (2016). Characterising urban growth in Tamale, Ghana: An analysis of urban governance response in infrastructure and service provision. Habitat International, 56,

109-123.

Ghana Statistical Service. (2014). 2010 Population Census, District analytical report. Ghana Statistical Service. Accra

Ghana Statistical Service (2014) 2010 Population and Housing Census: District Analytical Report. Prestea/Huni Valley District. Ghana Statistical Service. Accra

Gong, Hongmian, and James O. Wheeler. (2002). The location and suburbanization of business and professional services in the Atlanta area. Growth and Change 33, no. 3. 341-369.

Gordon, P., \& Richardson, H. W. (1996). Beyond polycentricity: the dispersed metropolis, Los Angeles, 1970-1990. Journal of the American Planning Association, 62(3), 289-295.

Gough, K. V., \& Yankson, P. (2011). A neglected aspect of the housing market: the caretakers of peri-urban Accra, Ghana. Urban Studies, 48(4), 793-810.

Guan, D., Li, H., Inohae, T., Su, W., Nagaie, T., \& Hokao, K. (2011). Modeling urban land use change by the integration of cellular automaton and Markov model. Ecological Modelling, 222(20-22), 3761-3772.

Harris, C. D., \& Ullman, E. L. (1945). The nature of cities. The Annals of the American Academy of Political and Social Science, 242(1), 7-17.

Hess Jr, G. A. (1995). Restructuring Urban Schools. A Chicago Perspective. The Series on School Reform. Teachers College Press, 1234 Amsterdam Ave., New York, NY 10027 (paperback: ISBN-0-8077-3475-6; clothbound: ISBN-0-8077-3476-4).

Hoyt, H. (1964). Recent distortions of the classical models of urban structure. Land economics, 40(2), 199-212.

Hoyt, H. (1939). The structure and growth of residential areas in American cities. US Government Printing Office. Washington, DC

Kleemann, J., Inkoom, J. N., Thiel, M., Shankar, S., Lautenbach, S., \& Fürst, C. (2017). Peri-urban land use pattern and its relation to land use planning in Ghana, West Africa. Landscape and Urban Planning, 165, 280-294.

Korah, P. I., \& Cobbinah, P. B. (2017). Juggling through Ghanaian urbanisation: flood hazard mapping of Kumasi. GeoJournal, 82(6), 1195-1212.

Korah, P. I., Cobbinah, P. B., \& Nunbogu, A. M. (2017). Spatial planning in Ghana: Exploringthe contradictions. Planning practice \& research, 32(4), 361-384.

Kpienbaareh, D., \& Luginaah, I. (2019). Modeling the internal structure, dynamics and trends of urban sprawl in Ghanaian cities using remote sensing, spatial metrics and spatial analysis. African Geographical Review, 1-19.

Mabogunje, A. L. (1968). Urbanization in Nigeria (pp. 96-101). London: University of London Press.

McDonagh, C. S., \& McDonagh, J. M. (1995). Valuing a target's ability to compete in the market. Mergers \& Acquisitions: The Dealermaker's Journal, 30(2), 22-25.

McDonagh, J. (2007). Theories of urban land use and their application to the Christchurch property market.

Ministry of Land and Natural Resources (2015). Ghana National Spatial Development Framework (2015-2035). Volume II: Overall Spatial Development Strategy. Accra. Ministry of Land and Natural Resources.

Owens, B. R. (2012). Mapping the city: Innovation and continuity in the Chicago School of Sociology, 1920-1934. The American Sociologist, 43(3), 264-293.

Owusu-Ansah, J. K., \& O’Connor, K. (2006). Transportation and physical development around Kumasi, Ghana. World academy of science, engineering and technology, 17, 129-134.

Petrov, L. O., Lavalle, C., \& Kasanko, M. (2009). Urban land use scenarios for a tourist region in Europe: Applying the MOLAND model to Algarve, Portugal. Landscape and Urban Planning, 92(1), 10-23. 
Reginster, I., \& Rounsevell, M. (2006). Scenarios of future urban land use in Europe. Environment and Planning B: Planning and Design, 33(4), 619-636.

Tim Hall. (2006) Urban Geography, Third Edition. Routledge. USA and Canada. ISBN10: 0-41534445-X ISBN13: 9-78-0-415-34445-6 (hbk).

Ubink, J. M., \& Quan, J. F. (2008). How to combine tradition and modernity? Regulating customary land management in Ghana. Land use policy, 25(2), 198-213.

U.N. Habitat (2016). Urbanization and development: emerging futures. World cities report, 3(4), 451.

Waddell, P., \& Ulfarsson, G. F. (2004). Introduction to urban simulation: Design and development of operational models. Handbook in transport, 5, 203-236.

Yeh, A. G. O., \& Wu, F. (1996). The new land development process and urban development in Chinese cities. International Journal of Urban and Regional Research, 20(2), 330-353. 